\title{
Evaluating the March 27, 2013 M 6.2 Earthquake Hypocenter Using Momentary High-Conductivity Materials
}

\author{
Chieh-Hung Chen ${ }^{1, *}$, Cheng-Horng Lin ${ }^{2}$, Han-Lun Hsu ${ }^{3}$, Chung-Ho Wang ${ }^{2}$, Lou-Chuang Lee ${ }^{2}$, \\ Peng $\operatorname{Han}^{4}$, Strong Wen ${ }^{5}$, and Chow-Son Chen ${ }^{3}$ \\ ${ }^{1}$ Department of Earth and Environmental Sciences, National Chung Cheng University, Chiayi, Taiwan \\ ${ }^{2}$ Institute of Earth Sciences, Academia Sinica, Taipei, Taiwan \\ ${ }^{3}$ Institute of Geophysics, National Central University, Jhongli, Taiwan \\ ${ }^{4}$ Graduate School of Science, Chiba University, Chiba, Japan \\ ${ }^{5}$ National Center for Research on Earthquake Engineering, Taipei, Taiwan
}

Received 31 July 2013, revised 2 April 2014, accepted 19 August 2014

\begin{abstract}
Seismo-magnetic anomalies induced from the momentary existence of current and/or high-conductivity materials have been widely reported. The Parkinson vectors derived from 3-component geomagnetic data at 3 stations were obtained via the magnetic transfer function and discussed with respect to the location $\left(23.90^{\circ} \mathrm{E}, 121.07^{\circ} \mathrm{N}\right)$ and the depth $(15.1 \mathrm{~km})$ of the M 6.2 earthquake on March 27, 2013 in Taiwan. Azimuth distribution constructed from the entire Parkinson vectors during the observation period is utilized to estimate the persistent background (i.e., the coast effect and underlying inhomogeneous tectonic structures) at each station. The normalized background distribution is subtracted from the normalized monitoring distributions computed using the azimuths of the Parkinson vectors within a 15-day moving window to determine the anomalous azimuths of high-conductivity materials. The depth ranges of high-conductivity materials are evaluated when the magnetic transfer function is subjected to the skin effect. The analytical results show that high-conductivity materials appeared in areas $\left(121.25^{\circ} \mathrm{E}, 23.70^{\circ} \mathrm{N}\right)$ and about $10-25 \mathrm{~km}$ in depth. The location of the high-conductivity materials is about $32 \mathrm{~km}$ away from the epicenter reported by the Central Weather Bureau and well covers the hypocenter depth. The agreement sheds lights on forecasting locations and hypocenter depths of forthcoming earthquakes via momentary existence of earthquake-related high-conductivity materials.
\end{abstract}

Key words: Seismo-electromagnetic anomalies, Parkinson vectors, Magnetic transform function, Skin effect

Citation: Chen, C. H., C. H. Lin, H. L. Hsu, C. H. Wang, L. C. Lee, P. Han, S. Wen, and C. S. Chen, 2015: Evaluating the March 27, 2013 M 6.2 earthquake hypocenter using momentary high-conductivity materials. Terr. Atmos. Ocean. Sci., 26, 1-9, doi: 10.3319/TAO.2014.08.19.01(GRT)

\section{INTRODUCTION}

Taiwan is located in the western margin of the Pacificrim seismic zone. The Philippine Sea Plate subducts northward beneath the Eurasian Plate along the Ryukyu Trench forming the Okinawa Trough spreading toward northeastern Taiwan (Tsai et al. 1977; Wu 1978). By contrast, the South China Sea Plate subducts eastward beneath the Philippine Sea Plate along the Manila Trench making up the Luzon arc toward southern Taiwan. Intense interactions between these plates result in complex tectonic structures (Ho 1988) and high seismicity in Taiwan. Eight ground-based proton mag-

\footnotetext{
* Corresponding author

E-mail:nononochchen@gmail.com
}

netometers were established in 1989 and routinely monitor changes in the geomagnetic total intensity field with a sampling interval of 5 or 10 minutes (Yen et al. 2004; Chen et al. 2009). These proton magnetometers were set in either plains or foothills along the Central Mountain Range. The locations of these magnetic stations were chosen carefully to avoid the disturbances caused by visible iron, power lines and human activity. In 1999, a destructive earthquake (the M 7.6 Chi-Chi earthquake; September 20, 1999 UTC) occurred in Central Taiwan with a casualty rate of more than two thousand people (Ma et al. 1999). Great seismo-magnetic anomalies (>150 nT) were observed at two magnetic stations (i.e., LY and TW; Fig. 1) located at the northern and southern ends of the Chelungpu fault during the Chi-Chi earthquake 
(Yen et al. 2004). High-performance proton magnetometers with a sampling rate of 1 minute replaced the original ones in 2002 (Yen et al. 2009) to study in-depth seismo-magnetic anomalies. Three stations ( $\mathrm{YH}, \mathrm{SL}$, and $\mathrm{PT}$ ) were installed from north to south along the Central Mountain Range. The Kinmen (KM) station replaced the Lunping (LP) station $\left(25.000^{\circ} \mathrm{E}, 121.167^{\circ} \mathrm{N}\right)$ as the reference station due to intense artificial disturbances resulted from city development. One magnetometer was installed at National Chung Cheng University in 2005 (i.e., the CCU station, $23.599^{\circ} \mathrm{E}$, $121.421^{\circ} \mathrm{N}$ ) to provide potential 3-component flux magnetic data with a 1-minute sampling interval. Three-component flux magnetic data are therefore available to study the coast effect and underlying inhomogeneous structures as well as determination regarding with anomalous earthquake direction in southwestern Taiwan. The CCU station sampling interval was significantly upgraded to 1-second in 2012.

Seismo-magnetic anomalies have been widely observed and reported in many major earthquakes (Fraser-Smith et al. 1990; Bernardi et al. 1991; Molchanov et al. 1992; Kopytenko et al. 1993; Hayakawa et al. 1996, 1999, 2000; Kawate et al. 1998; Gotoh et al. 2002; Hattori et al. 2002, 2004a, b, 2013; Liu et al. 2006; Molchanov and Hayakawa 2008; Chen et al. 2009, 2010, 2011a, 2012, 2013a; Han et al. 2011; Wen et al. 2012). These anomalies are generally considered to be caused by the momentary existence of electric currents along faults (Yen et al. 2004), sudden changes in conductivity (Zeng et al. 1995; Merzer and Klemperer 1997) and/or fluctuations in susceptibility near epicenters (Stacey 1962; Nagata 1970; Liu et al. 2006; Wen et al. 2012) due to the accumulation of earthquake-related stress on nearby rock beds. Chen et al. (2013a) computed Parkinson vectors using the 3-component data recorded at the CCU station via the magnetic transfer function (Parkinson and Jones 1979) to examine the change in conductivity relating to earthquakes. It was found that the Parkinson vectors generally direct toward source locations, where underlying conductivity is higher than its neighborhood. Analytical results showed that the Parkinson vector orientations point toward epicenters a few days before and after earthquakes when the interference raised by the coast effect and underlying electrical structure is mitigated. A hypothesis has been proposed that conductivity nearby hypocenters can be enhanced due to earthquakerelated stress disturbance.

Two more 3-component magnetometers were installed in northern (YMM $\left.121.561^{\circ} \mathrm{E}, 25.155^{\circ} \mathrm{N}\right)$ and eastern (HLG $121.421^{\circ} \mathrm{E}, 23.599^{\circ} \mathrm{N}$ ) Taiwan at the end of 2012 , forming a distinct network along with the original CCU site. A M 6.2 earthquake $\left(23.90^{\circ} \mathrm{E}, 121.07^{\circ} \mathrm{N}\right)$ timely occurred on March 27, 2013 in Central Taiwan and was thus used as a unique case to examine whether the orientations of Parkinson vectors at the CCU, HLG, and YMM stations could be used to jointly locate the earthquake epicenter. The $1-$ and $10-\mathrm{Hz}$ 3 -component magnetic data recorded at the 3 stations were computed strictly following the method proposed in Chen et al. (2013a) to retrieve anomalous Parkinson vector orientations via the magnetic transfer function. Anomalous orientations at the 3 stations were then compared with earthquake azimuths to vigorously test the hypothesis. Interlaced maps were constructed using anomalous Parkinson vector orientations from the CCU, HLG, and YMM stations, and the experimental epicenter locations were compared with the officially-reported epicenter location to examine the validity and practicability of the proposed analytical method.

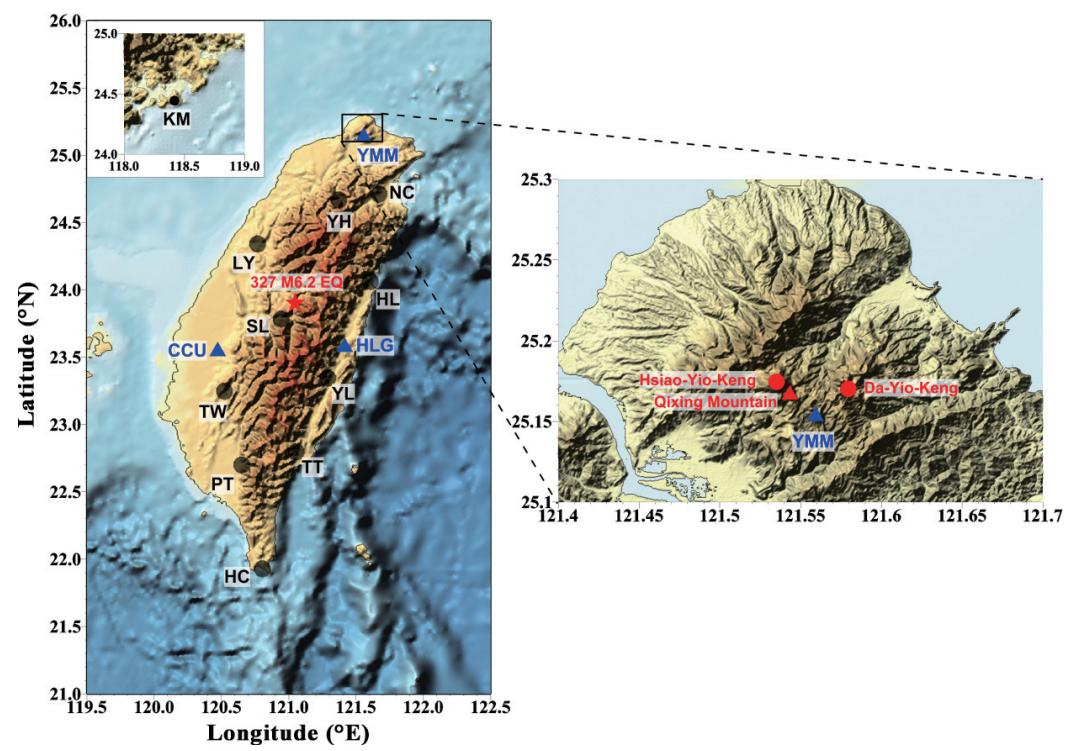

Fig. 1. Magnetometer locations in Taiwan with a topographic map. Black dots denote locations of the proton magnetometers. Blue triangles are locations of 3-component flux magnetometers. The red star is the epicenter of the M 6.2 earthquake on March 27, 2013. Note that absolute and relative magnetic data are all observed at HLG, YMM, and CCU stations, respectively. 


\section{METHODOLOGY}

Chen et al. (2013a) proposed that the hypocenter depth can be roughly estimated using the 3-component magnetic data via magnetic transfer function when the relationship between the depth and frequency (i.e., the skin depth) in a certain region near a magnetometer can be understood. In this work, the skin depths near the CCU, YMM and HLG stations were derived from magnetotelluric data observed nearby or previous studies (Bertrand et al. 2009; Chiang et al. 2010). The hypocenter depth of the target earthquake (i.e., M 6.2 on March 27, 2013; UTC) reported by the Central Weather Bureau, Taiwan was $15.1 \mathrm{~km}$. Parkinson vectors derived from magnetic data at particular stations within frequency bands (Table 1) associated with $15 \mathrm{~km}$ deep were used as an example to examine momentary anomalies inducted by the M 6.2 earthquake in the geomagnetic field. Magnetic data recorded during the nocturnal time (21:00 - 3:00) were utilized in this work to avoid the influence from solar and human activity. The data were transferred into the frequency domain using the Fourier transform via a temporal moving window of $3 \mathrm{~h}$ with a 1-minute step to compute associated amplitude adapting the magnetic transfer function. Parkinson vectors were regularly calculated from obtained amplitudes every 2 minutes. The total number for the Parkinson vectors is 180 each day.

When Parkinson vectors are utilized to study seismoconductivity anomalies in an island area, the magnetic coast effect and inhomogeneous underlying structures must be taken into consideration. The coast effect mechanisms (Parkinson and Jones 1979; DeLaurier et al. 1983; Parkinson 1983) are caused by induction fields resulted from the different conductivity properties of the sea water, oceanic and continental lithosphere (Ogawa et al. 1986; Hitchman et al. 2000; Armadillo et al. 2001). The coast effect prompts the Parkinson vectors to point toward the high-conductivity sea water and remain orthogonal to the nearby coastline. Meanwhile, Parkinson vectors often point toward relative high-conductivity areas due to inhomogeneous underlying structure. Responses of the coast effect and inhomogeneous structure on Parkinson vectors are assumed to be persistent in the short study period. The background distribution can be constructed using azimuths from the entire Parkinson vectors during the observation period for a station to understand the persistent factors (i.e., the coast effect and inhomogeneous structure). By contrast, the monitoring distribution is computed using Parkinson vector azimuths within a 15-day moving window for a station to expose the temporal changes in conductivity surroundings. Both the background and monitoring azimuth distributions are binned by each $10^{\circ}$ and self-normalized. The normalized background distributions are subtracted from the normalized monitoring distributions at each bin to mitigate the persistent factors of a station. The anomalous proportions can thus be further calculated using the residual to the normalized background distribution at particular bins and are then compared with the earthquake azimuths. Note that the positive anomalous proportion denotes that Parkinson vectors have a higher tendency to the momentary existence of high-conductivity materials in a particular direction.

\section{INTERPRETATIONS}

Figure 2 shows the background distributions at a depth of $15 \mathrm{~km}$ to reflect the coast effect and inhomogeneous structure responses on Parkinson vectors at the 3 stations.

Table 1. Locations and relationships between the frequency and associated depths at the 3 stations. Notably, it is difficult to retrieve the relationships between the frequency and associated depths in areas where are very close to epicenters before earthquake occurrence. The relationships between frequency and associated depths close to particular magnetometers are utilized to enhance the accuracy in depths for earthquakes occurring close to stations

\begin{tabular}{|c|c|c|c|c|c|c|}
\hline & \multicolumn{6}{|c|}{ Station } \\
\hline & \multicolumn{2}{|c|}{$\mathrm{CCU}$} & \multicolumn{2}{|c|}{ HLG } & \multicolumn{2}{|c|}{ YMM } \\
\hline & Long. $\left({ }^{\circ} \mathbf{E}\right)$ & Lat. $\left({ }^{\circ} \mathbf{N}\right)$ & Long. $\left({ }^{\circ} \mathbf{E}\right)$ & Lat. $\left({ }^{\circ} \mathbf{N}\right)$ & Long. $\left({ }^{\circ} \mathbf{E}\right)$ & Lat. $\left({ }^{\circ} \mathbf{N}\right)$ \\
\hline & 120.479 & 23.566 & 121.561 & 25.155 & 121.421 & 23.599 \\
\hline Associated Depth $(\mathrm{km})$ & \multicolumn{2}{|c|}{ Frequency $(\mathrm{Hz})$} & \multicolumn{2}{|c|}{ Frequency $(\mathrm{Hz})$} & \multicolumn{2}{|c|}{ Frequency $(\mathrm{Hz})$} \\
\hline 5 & \multicolumn{2}{|c|}{0.39658} & \multicolumn{2}{|c|}{1.69420} & \multicolumn{2}{|c|}{0.03868} \\
\hline 10 & \multicolumn{2}{|c|}{0.10772} & \multicolumn{2}{|c|}{0.67494} & \multicolumn{2}{|c|}{0.01076} \\
\hline 15 & \multicolumn{2}{|c|}{0.04269} & \multicolumn{2}{|c|}{0.39376} & \multicolumn{2}{|c|}{0.00504} \\
\hline 20 & \multicolumn{2}{|c|}{0.02115} & \multicolumn{2}{|c|}{0.23358} & \multicolumn{2}{|c|}{0.00285} \\
\hline 25 & \multicolumn{2}{|c|}{0.01254} & \multicolumn{2}{|c|}{0.13695} & \multicolumn{2}{|c|}{0.00187} \\
\hline 30 & \multicolumn{2}{|c|}{0.00828} & \multicolumn{2}{|c|}{0.08790} & \multicolumn{2}{|c|}{0.00133} \\
\hline
\end{tabular}




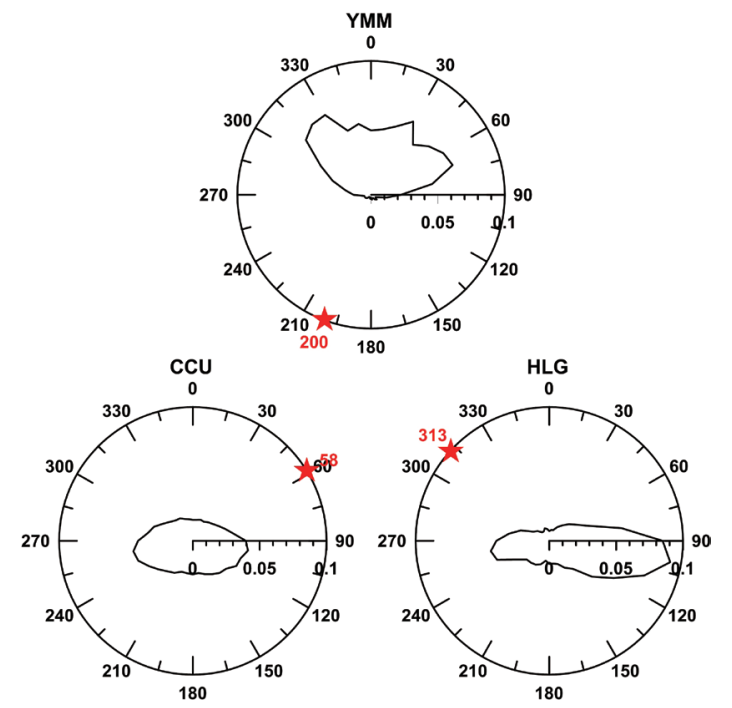

Fig. 2. The background distributions of Parkinson vectors at the CCU, HLG, and YMM stations. The radius denotes the normalized proportion of Parkinson vectors at particular azimuths. Numbers near red stars show earthquake azimuths of the M 6.2 earthquakes at respective stations.

The Parkinson vector orientations concentrate mainly at about 255 and $90^{\circ}$ directing toward the western and eastern side of the CCU station, respectively. An azimuth of about $255^{\circ}$ points to sea water and is roughly orthogonal to the strike $\left(169^{\circ}\right)$ of the coast line nearest the CCU station in agreement with the coast effect. A direction of approximately $90^{\circ}$ agrees with the location of relative high-conductivity materials beneath the Central Mountain Range observed by the magnetotelluric survey (Chiang et al. 2010). In terms of the normalized background distribution at the HLG station, orientations of Parkinson vectors at about 90 and $270^{\circ}$ rightly point toward the eastern and western side, respectively. The directions of approximately 90 and $270^{\circ}$ are resulted from the coast effect and the existence of relative high-conductivity materials beneath the Central Mountain Range, respectively.

The Parkinson vector orientations from the YMM station located in the volcanic area at the northern tip of Taiwan direct mainly to the azimuth of about $320^{\circ}$ pointing toward Qixing Mountain and/or Hsiao-Yio-Keng (Fig. 2; also see Fig. 1 for site locations). The secondary peak $\left(\sim 70^{\circ}\right)$ points toward the southern part of Da-Yio-Keng. Lin (2006) reported that a magma chamber lies under the area between HsiaoYio-Keng and Da-Yio-Keng. Chen (2008) investigated this area using a magnetotelluric survey and confirmed relative high-conductivity materials surrounding the underlying magma chamber. Hence, the Parkinson vectors at YMM pointing mainly toward Hsiao-Yio-Keng and Da-Yio-Keng are subjected to the underlying inhomogeneous structure and consistent with the previous surveys (Lin 2006; Chen 2008). Note that the strike of the nearby coast line is about $135^{\circ}$ for the YMM station. A rather small peak at about $30^{\circ}$ that can be retrieved from the background distribution is primarily due to the coast effect.

Figure 3 reveals the anomalous proportions at $15 \mathrm{~km}$ depth in these 3 stations associated with the M 6.2 earthquake. The Parkinson vectors in the anomalous proportions at the YMM station were concentrated mainly at azimuths of about 100 and $240^{\circ}$ during March 8 - 26 due to nearby small earthquakes (Fig. 3a; also see the entire earthquake catalog at http://www.cwb.gov.tw). On March 14, 2013 the anomalous proportions were significantly enhanced at the azimuth of about $190^{\circ}$ in agreement with the earthquake azimuth to the YMM station (Fig. 3a). No significant azimuth could be retrieved from positive anomalous proportions at the $\mathrm{CCU}$ station before March 12, 2013 (Fig. 3b). The anomalous proportions were enhanced after March 12, 2013 at azimuths ranging from $20-45^{\circ}$, which is close to the earthquake azimuth to the CCU station. The anomalous proportions were also enhanced at inverse directions ranging from $210-240^{\circ}$, which shifted slightly to the range from $270-300^{\circ}$ after March 21, 2013. The anomalous proportions at azimuths of about 0,100 , and $180^{\circ}$ increased at the HLG station during March 8 - 16, 2013 (Fig. 3c). Quantities of the anomalous proportions became denser and anomalous azimuths shifted slightly to a narrow band between $120-140^{\circ}$ that agree with the anti-earthquake azimuths $\left(133^{\circ}\right)$ but do not agree well with the earthquake azimuth $\left(313^{\circ}\right)$ referred to the HLG station. The maximum anomalous proportion between the azimuth and the anti-azimuth is utilized in this work to effectively determine anomalous azimuths associated with a particular earthquake.

Figures $4 \mathrm{a}, \mathrm{b}$, and $\mathrm{d}$ reveal the anomaly radiation maps in the spatial domain using anomalous proportions at depth of $15 \mathrm{~km}$ in the YMM, CCU, and HLG stations 1 day before the M 6.2 earthquake. There are two and/or three anomalous azimuths that can be found from the radiation map after removing the background disturbance for each station. It is reasonable to find one of them directing toward the epicenter at the respective station consistent with analytical results using one station shown in Fig. 3 and/or as reported in Chen et al. (2013a). However, earthquake causal mechanisms and high-conductivity anomalies are always not the same both in temporal and spatial scales. Areas with high-conductivity anomalies obtained from magnetic data can be close to the epicenters and/or the hypocenters determined via seismic waves; but they often show a difference in reality. To determine the most potential anomalous region, the anomaly radiation maps can be superimposed as an integrated map shown in Fig. $4 \mathrm{c}$ via the averaging process. It is obvious that anomalous azimuths, which point to directions away from the epicenter, can thus be significantly reduced through overlapping. At the end, a crossing area from the interlaced section (i.e., $121.25^{\circ} \mathrm{E}, 23.7^{\circ} \mathrm{N}$ ) is found at a distance of about $32 \mathrm{~km}$ away from the epicenter. Figure 5 further 
shows the integrated maps from depths of 5 - $30 \mathrm{~km}$ using magnetic data through particular frequency bands (Table 1). It is clear that the interlaced sections derived from depths of
$10-25 \mathrm{~km}$ are close to the officially-reported hypocenter depth of the M 6.2 earthquake, except for the $20 \mathrm{~km}$ depth. These results provide positive and encouraging evidences to (a)

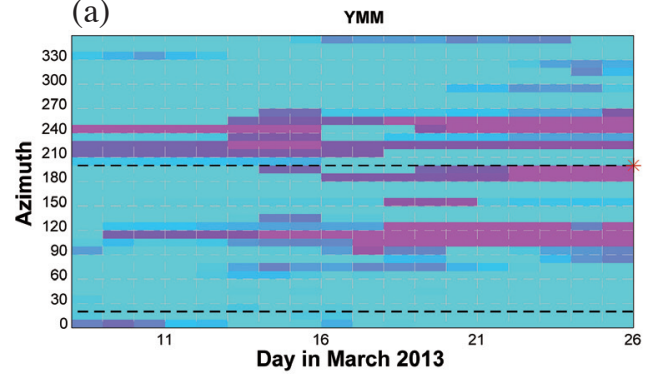

(c) (b)

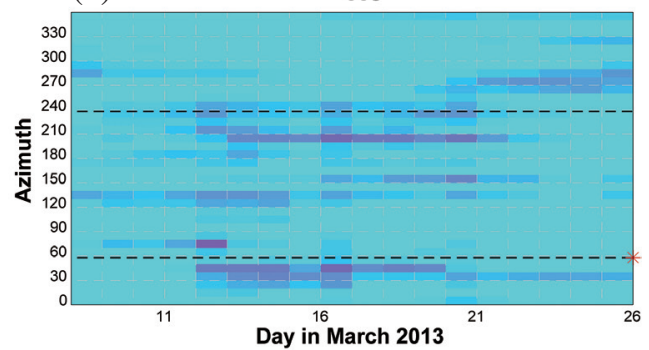

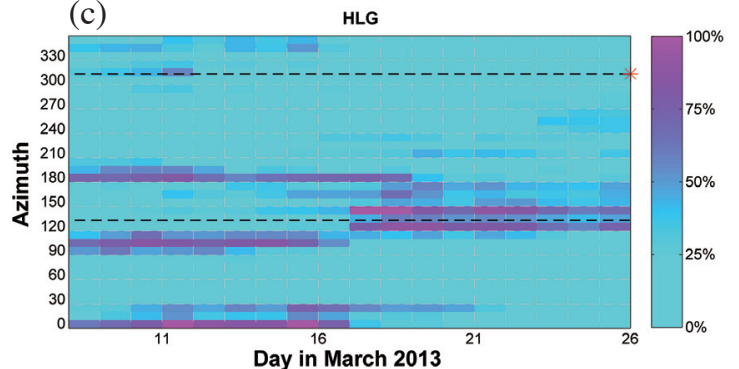

Fig. 3. The anomalous proportions at the (a) YMM, (b) CCU and (c) HLG stations from March 8 - 26, 2013. The dash lines denote azimuths toward either earthquake azimuths (with the red star on earthquake day) or anti-earthquake azimuths.
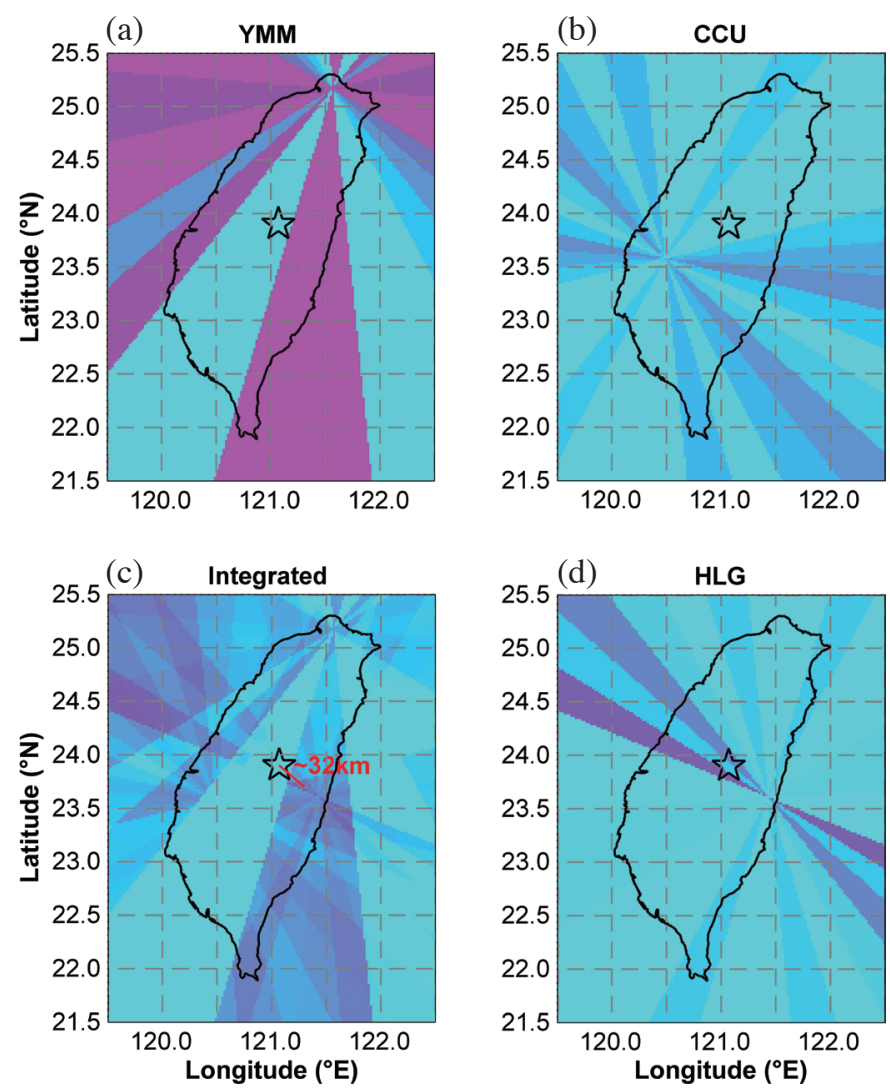

Fig. 4. The radiation maps in the (a) YMM, (b) CCU, (d) HLG stations, and the (c) intergrade map on March 26, 2013. The open star shows the epicenter of the M 6.2 earthquake. 

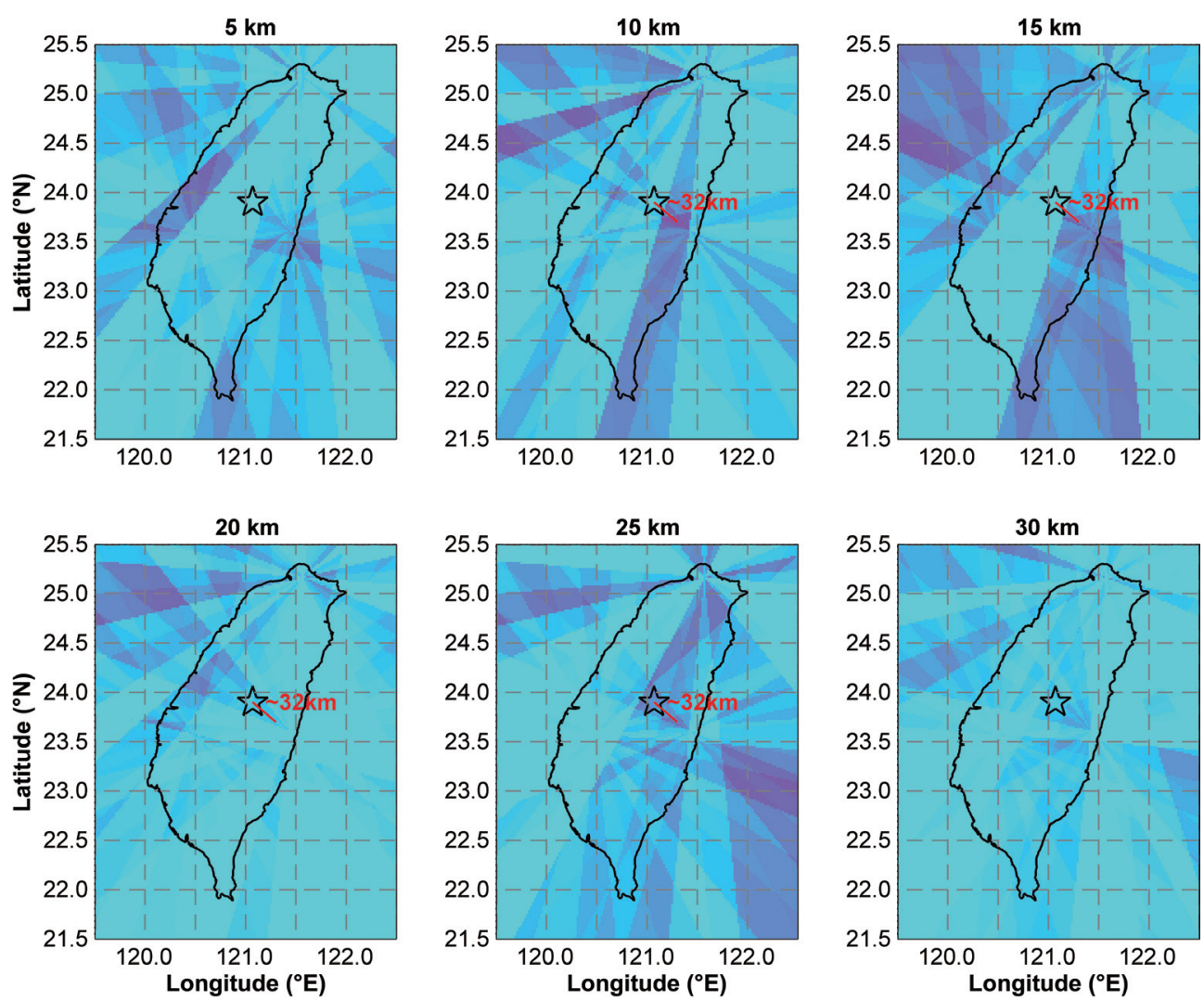

Fig. 5. The interlaced maps with respect to depth ranged from 5 - $30 \mathrm{~km}$. The open star shows the epicenter of the M 6.2 earthquake.

support the momentary existence of relative high-conductivity near the hypocenter during the M 6.2 earthquake.

\section{DISCUSSION AND CONCLUSIONS}

High-conductivity materials would appear before major earthquakes and have been widely reported in many previous studies via magnetotelluric equipment and/or magnetometers (Lin and Zeng 1993; Chen and Chen 2000; Honkura et al. 2000). Merzer and Klemperer (1997) modeled low-frequency magnetic-field precursors to the Loma Prieta Earthquake with a significant increase in fault-zone conductivity. Those studies suggest that the current and/ or high-conductivity materials often exist near epicenters and/or along major faults during earthquakes. Magnetic enhancements of high-conductivity materials would be caused by changes in rock susceptibilities and/or conductivities due to earthquake-related stress accumulation (Stacey 1962; Nagata 1970). Although causal mechanisms of the conductivity enhancement are not yet fully understood, it has been proposed that the electrokinetic (Fenoglio et al. 1995), micro-fracturing effects (Molchanov and Hayakawa 1995) and carriers of positive hole charges in rocks (Freund 2011) may all play various roles in this process. However, high conductivity material areas and quantifications are frequently very diverse for different earthquakes and are very difficult to observe due to the transient nature of high-conductivity anomalies.

Note that many small earthquakes occurred in high seismicity Taiwan during the study period. The anomalous proportions are simultaneously affected by the target earthquake (on March 27, 2013) and the other small events in our work, such as the anomalous proportions at about $120^{\circ}$ at the YMM station from March 9 - 26, 2013 related to earthquakes that occurred in southeastern (Ilan) areas (also see http://www.cwb.gov.tw). The appearance of the anomalous proportions is not limited to specific anomalies for a particular earthquake but is combined by the joined results of high-conductivity materials during the study period. Thus, changes in the anomalous proportions at 3 respective stations sometimes do not occur at the same time. While the effects of a major earthquake on the anomalous proportions are significantly larger than those of small events surrounding particular areas, the anomalous azimuths, which direct and/or inversely direct toward the same earthquake, can be confidently obtained. Thus, the proposed method has benefit in determining the epicenters of major (small) earthquakes in high-seismicity (low-seismicity) periods. A 15-day running window also affects the changes in the anomalous proportions. The earthquake related high-conductivity materials can be meaningfully determined if the high-conductivity anomalies exist and last for a certain long period. 
One significant feature observed in this study is that the orientation of Parkinson vectors is often toward either earthquake azimuths or anti-earthquake azimuths. This feature would be caused by unstable induction fields generated by earthquakes and data analysis processes. Fraser-Smith et al. (1990) reported changes in the magnetic field in a lowfrequency range near the epicenter of the $\mathrm{M}_{\mathrm{s}} 7.1$ Loma Prieta earthquake. Although significant enhancements can be found several days before the Loma Prieta earthquake, obvious fluctuations can also be observed along the enhanced amplitude. This suggests that the low-frequency band geomagnetic field is certainly affected by the earthquake. However, the intensity of an earthquake-related magnetic disturbance is unstable and does change along with time. The orientations of Parkinson vectors are deduced from a change tendency in the amplitude of magnetic fields during the study interval. Thus, Parkinson vector orientations would point toward the earthquake azimuths when earthquake-related induction field enhancements are primarily utilized in data analytical processes. In contrast, Parkinson vectors oriented toward the anti-earthquake azimuths are caused mainly by the decrease in earthquake-related induction field.

Currently, an automatic-process system comprised of these 3 stations has been established in Taiwan to routinely monitor changes in high-conductivity anomalies. Based on the observation experiences from 2012 - 2013, high-conductivity anomalies can be more confidently located by the overlap of multiple stations. High-conductivity anomalies generally appear several days before earthquakes. Highconductivity anomaly locations often exist with a distance difference $<50 \mathrm{~km}$ to epicenters. The appearance of highconductivity anomalies and pre-earthquake changes in total electric content anomalies (Liu et al. 2011) would yield a constant and positive relationship. The existence of highconductivity anomalies is further compared with residual surface displacement (Chen et al. 2011b, 2013b, 2014), which can be utilized to understand stress accumulation and expose potential mechanisms before strong earthquakes. Two additional stations will be installed in Western Taiwan in 2015 to increase the spatial resolution accuracy and further construct a 3-D map of high-conductivity changes with respect to the seismic activity. Statistical results will be reported when satisfactory and interesting results have been accumulated through time.

In conclusion, conductivity enhancements near the hypocenter have been well observed in thrust-type earthquakes due to compression mechanisms (also see Liu et al. 2006; Chen et al. 2013a). Geomagnetic data can be utilized to determine the potential location and depth-range of earthquake-related high-conductivity materials via the magnetic transfer function prior to the earthquake occurrence. Earthquake-related high-conductivity materials are very distinct with the hypocenter in terms of physical characteristics. High-conductivity materials and hypocenters generally yield a short-distance discrepancy $(\sim 50 \mathrm{~km})$ rather than complete overlap. The momentary existence of earthquake-related high-conductivity materials provides valuable information on the timing and location for earthquake forecasting, particularly for thrust-type earthquakes and in areas dominated by compression stress.

Acknowledgements The authors wish to thank Profs. ChienChih Chen and Horng-Yuan Yen at National Central University for their useful suggestions and express our sincere appreciation to the Central Weather Bureau for providing the complete earthquake catalog. The National Science Council of the Republic of China financially supports this research under Contracts MOST 100-2116-M-001-027-MY3, 1032116-M-194-006, and 103-2116-M-194 -015-MY3.

\section{REFERENCES}

Armadillo, E., E. Bozzo, V. Cerv, A. De Santis, D. Di Mauro, M. Gambetta, A. Meloni, J. Pek, and F. Speranza, 2001: Geomagnetic depth sounding in the Northern Apennines (Italy). Earth Planets Space, 53, 385-396, doi: 10.1186/BF03352395. [Link]

Bernardi, A., A. C. Fraser-Smith, P. R. McGill, and O. G. Villard Jr., 1991: ULF magnetic field measurements near the epicenter of the $M_{\mathrm{s}}$ 7.1 Loma Prieta earthquake. Phys. Earth Planet. Inter., 68, 45-63, doi: 10.1016/0031-9201(91)90006-4. [Link]

Bertrand, E., M. Unsworth, C. W. Chiang, C. S. Chen, C. C. Chen, F. Wu, E. Türkoğlu, H. L. Hsu, and G. Hill, 2009: Magnetotelluric evidence for thick-skinned tectonics in central Taiwan. Geology, 37, 711-714, doi: 10.1130/G25755A.1. [Link]

Chen, C. H., J. Y. Liu, W. H. Yang, H. Y. Yen, K. Hattori, C. R. Lin, and Y.H. Yeh, 2009: SMART analysis of geomagnetic data observed in Taiwan. Phys. Chem. Earth, 34, 350-359, doi: 10.1016/j.pce.2008.09.002. [Link]

Chen, C. H., J. Y. Liu, P. Y. Lin, H. Y. Yen, K. Hattori, W. T. Liang, Y. I. Chen, Y. H. Yeh, and X. Zeng, 2010: Pre-seismic geomagnetic anomaly and earthquake location. Tectonophysics, 489, 240-247, dio: 10.1016/j. tecto.2010.04.018. [Link]

Chen, C. H., S. Wen, J. Y. Liu, T. K. Yeh, C. H. Wang, H. Y. Yen, K. Hattori, and C. R. Lin, 2011a: Seismomagnetic signal comparison using the Morlet wavelet method. Disaster Adv., 4, 53-60.

Chen, C. H., T. K. Yeh, J. Y. Liu, C. H. Wang, S. Wen, H. Y. Yen, and S. H. Chang, 2011b: Surface deformation and seismic rebound: Implications and applications. Surv.Geophys.,32, 291-313, doi: 10.1007/s10712-011-9117-3. [Link]

Chen, C. H., J. Y. Liu, T. M. Chang, T. K. Yeh, C. H. Wang, S. Wen, H. Y. Yen, K. Hattori, C. R. Lin, and Y. R. Chen, 2012: Azimuthal propagation of seismo-magnetic 
signals from large earthquakes in Taiwan. Ann. Geophys., 55, 63-71, doi: 10.4401/ag-5326. [Link]

Chen, C. H., H. L. Hsu, S. Wen, T. K. Yeh, F. Y. Chang, C. H. Wang, J. Y. Liu, Y. Y. Sun, K. Hattori, H. Y. Yen, and P. Han, 2013a: Evaluation of seismo-electric anomalies using magnetic data in Taiwan. Nat. Hazards Earth Syst. Sci., 13, 597-604, doi: 10.5194/nhess13-597-2013. [Link]

Chen, C. H., S. Wen, T. K. Yeh, C. H. Wang, H. Y. Yen, J. Y. Liu, Y. Hobara, and P. Han, 2013b. Observation of surface displacements from GPS analyses before and after the Jiashian earthquake $(M=6.4)$ in Taiwan. J. Asian Earth Sci., 62, 662-671, doi: 10.1016/j. jseaes.2012.11.016. [Link]

Chen, C. H., S. Wen, J. Y. Liu, K. Hattori, P. Han, Y. Hobara, C. H. Wang, T. K. Yeh, and H. Y. Yen, 2014: Surface displacements in Japan before the 11 March 2011 M9.0 Tohoku-Oki earthquake. J. Asian Earth Sci., 80, 165-171, doi: 10.1016/j.jseaes.2013.11.009. [Link]

Chen, C. S., 2008: Investigation and Monitoring of Underground Magma Chamber of the Datun Volcano Group: Magnetotelluric Survey Method, Yangmingshan National Park Headquarters, Taiwan. (in Chinese)

Chen, C. S. and C. C. Chen, 2000: Magnetotelluric soundings of the source area of the 1999 Chi-Chi earthquake in Taiwan: Evidence of fluids at the hypocenter. Terr. Atmos. Ocean. Sci., 11, 679-688.

Chiang, C. W., C. C. Chen, M. Unsworth, E. Bertrand, C. S. Chen, T. D. Kieu, and H. L. Hsu, 2010: The deep electrical structure of southern Taiwan and its tectonic implications. Terr. Atmos. Ocean. Sci., 21, 879-895, doi: 10.3319/TAO.2010.02.25.01(T). [Link]

DeLaurier, J. M., D. R. Auld, and L. K. Law, 1983: The geomagnetic response across the continental margin off Vancouver Island: Comparison of results from numerical modelling and field data. J. Geomagn. Geoelectr., 35, 517-528, doi: 10.5636/jgg.35.517. [Link]

Fenoglio, M. A., M. J. S. Johnston, and J. D. Byerlee, 1995: Magnetic and electric fields associated with changes in high pore pressure in fault zones: Application to the Loma Prieta ULF emissions. J. Geophys. Res., 100, 12951-12958, doi: 10.1029/95JB00076. [Link]

Fraser-Smith, A. C., A. Bernardi, P. R. McGill, M. E. Ladd, R. A. Helliwell, and O. G. Villard Jr., 1990: Low-frequency magnetic field measurements near the epicenter of the $\mathrm{M}_{\mathrm{s}}$ 7.1 Loma Prieta earthquake. Geophys. Res. Lett., 17, 1465-1468, doi: 10.1029/GL017i009p01465. [Link]

Freund, F., 2011: Pre-earthquake signals: Underlying physical processes. J. Asian Earth Sci., 41, 383-400, doi: 10.1016/j.jseaes.2010.03.009. [Link]

Gotoh, K., Y. Akinaga, M. Hayakawa, and K. Hattori, 2002: Principal component analysis of ULF geomagnetic data for Izu islands earthquakes in July 2000. J. Atmos.
Electr., 22, 1-12.

Han, P., K. Hattori, Q. Huang, T. Hirano, Y. Ishiguro, C. Yoshino, and F. Febriani, 2011: Evaluation of ULF electromagnetic phenomena associated with the 2000 Izu Islands earthquake swarm by wavelet transform analysis. Nat. Hazards Earth Syst. Sci., 11, 965-970, doi: 10.5194/nhess-11-965-2011. [Link]

Hattori, K., Y. Akinaga, M. Hayakawa, K. Yumoto, T. Nagao, and S. Uyeda, 2002: ULF magnetic anomaly preceding the 1997 Kagoshima earthquakes.In: Hayakawa, M. and O. A. Molchanov (Eds.), Seismo Electromagnetics: Lithosphere-Atmosphere-Ionosphere Coupling, Terra Scientific Publishing Company, Tokyo, 478 pp.

Hattori, K., I. Takahashi, C. Yoshino, N. Isezaki, H. Iwasaki, M. Harada, K. Kawabata, E. Kopytenko, Y. Kopytenko, P. Maltsev, V. Korepanov, O. Molchanov, M. Hayakawa, Y. Noda, T. Nagao, and S. Uyeda, 2004a: ULF geomagnetic field measurements in Japan and some recent results associated with Iwateken Nairiku Hokubu earthquake in 1998. Phys. Chem. Earth, 29, 481-494, doi: 10.1016/j.pce.2003.09.019. [Link]

Hattori, K., A. Serita, K. Gotoh, C. Yoshino, M. Harada, N. Isezaki, and M. Hayakawa, 2004b: ULF geomagnetic anomaly associated with $2000 \mathrm{Izu}$ Islands earthquake swarm, Japan. Phys. Chem. Earth, 29, 425-435, doi: 10.1016/j.pce.2003.11.014. [Link]

Hattori, K., P. Han, C. Yoshino, F. Febriani, H. Yamaguchi, and C. H. Chen, 2013: Investigation of ULF seismomagnetic phenomena in Kanto, Japan during 20002010: Case studies and statistical studies. Surv. Geophys., 34, 293-316, doi: 10.1007/s10712-012-9215-х. [Link]

Hayakawa, M., R. Kawate, O. A. Molchanov, and K. Yumoto, 1996: Results of ultra-low-frequency magnetic field measurements during the Guam Earthquake of 8 August 1993. Geophys. Res. Lett., 23, 241-244, doi: 10.1029/95GL02863. [Link]

Hayakawa, M., T. Ito, and N. Smirnova, 1999: Fractal analysis of ULF geomagnetic data associated with the Guam Earthquake on August 8, 1993. Geophys. Res. Lett., 26, 2797-2800, doi: 10.1029/1999GL005367. [Link]

Hayakawa, M., T. Itoh, K. Hattori, and K. Yumoto, 2000: ULF electromagnetic precursors for an earthquake at Biak, Indonesia on February 17, 1996. Geophys. Res. Lett., 27, 1531-1534, doi: 10.1029/1999GL005432. [Link]

Hitchman, A. P., P. R. Milligan, F. E. M. Lilley, A. White, and G. S. Heinson, 2000: The total-field geomagnetic coast effect: The CICADA97 line from deep Tasman sea to inland New South Wales. Explor. Geophys., 31, 52-57, doi: 10.1071/EG00052. [Link]

Ho, C. S., 1988: An Introduction to the Geology of Taiwan: Explanatory Text of the Geologic Map of Taiwan, Central Geological Survey, Ministry of Economic Affairs, $2^{\text {nd }} \mathrm{Ed} ., 192 \mathrm{pp}$. 
Honkura, Y., A. M. Işikara, N. Oshiman, A. Ito, B. Üçer, Ş. Bariş, M. K. Tunçer, M. Matsushima, R. Pektaş, C. Çelik, S. B. Tank, F. Takahashi, M. Nakanishi, R. Yoshimura, Y. Ikeda, and T. Komut, 2000: Preliminary results of multidisciplinary observations before, during and after the Kocaeli (Izmit) earthquake in the western part of the North Anatolian Fault Zone. Earth Planets Space, 52, 293-298, doi: 10.1186/BF03351638. [Link]

Kawate, R., O. A. Molchanov, and M. Hayakawa, 1998: Ultra-low-frequency magnetic fields during the Guam earthquake of 8 August 1993 and their interpretation. Phys. Earth Planet. Inter., 105, 229-238, doi: 10.1016/ S0031-9201(97)00094-0. [Link]

Kopytenko, Y. A., T. G. Matiashvili, P. M. Voronov, E. A. Kopytenko, and O. A. Molchanov, 1993: Detection of ultra-low-frequency emissions connected with the Spitak earthquake and its aftershock activity, based on geomagnetic pulsations data at Dusheti and Vardzia observatories. Phys. Earth Planet. Inter., 77, 85-95, doi: 10.1016/0031-9201(93)90035-8. [Link]

Lin, C. H., 2006: Yangmingshan National Park Datun Volcano Group Potential Magma Chambers and LongTerm Microseismic Observation Network Monitoring Program (IV), Yangmingshan National Park Headquarters, Taiwan. (in Chinese)

Lin, Y. and X. Zeng, 1993: The response of anomalous short period geomagnetic variations to moderate-strong earthquakes in China. J. Earthq. Prediction Res., 2, 105-114.

Liu, J. Y., C. H. Chen, Y. I. Chen, H. Y. Yen, K. Hattori, and K. Yumoto, 2006: Seismo-geomagnetic anomalies and $M \geq 5.0$ earthquakes observed in Taiwan during 19882001. Phys. Chem. Earth, 31, 215-222, doi: 10.1016/j. pce.2006.02.009. [Link]

Liu, J. Y., H. Le, Y. I. Chen, C. H. Chen, L. Liu, W. Wan, Y. Z. Su, Y. Y. Sun, C. H. Lin, and M. Q. Chen, 2011: Observations and simulations of seismoionospheric GPS total electron content anomalies before the 12 January 2010 M7 Haiti earthquake. J. Geophys. Res., 116, A04302, doi: 10.1029/2010JA015704. [Link]

Ma, K. F., C. T. Lee, Y. B. Tsai, T. C. Shin, and J. Mori, 1999: The Chi-Chi, Taiwan earthquake: Large surface displacements on an inland thrust fault. Eos, Trans., $A G U, \mathbf{8 0}, 605-611$, doi: 10.1029/99EO00405. [Link]

Merzer, M. and S. L. Klemperer, 1997: Modeling low-frequency magnetic-field precursors to the Loma Prieta earthquake with a precursory increase in fault-zone conductivity. Pure Appl. Geophys., 150, 217-248, doi: 10.1007/s000240050074. [Link]

Molchanov, O. A. and M. Hayakawa, 1995: Generation of ULF electromagnetic emissions by microfracturing. Geophys. Res. Lett., 22, 3091-3094, doi:
10.1029/95GL00781. [Link]

Molchanov, O. A. and M. Hayakawa, 2008: Seismo-Electromagnetics and Related Phenomena: History and Latest Results, Terra Scientific Publishing Company, Tokyo, $190 \mathrm{pp}$.

Molchanov, O. A., Y. A. Kopytenko, P. M. Voronov, E. A. Kopytenko, T. G. Matiashvili, A. C. Fraser-Smith, and A. Bernardi, 1992: Results of ULF magnetic field measurements near the epicenters of the Spitak $\left(M_{s}=\right.$ 6.9) and Loma Prieta $\left(M_{s}=7.1\right)$ earthquakes: Comparative analysis. Geophys. Res. Lett., 19, 1495-1498, doi: 10.1029/92GL01152. [Link]

Nagata, T., 1970: Anisotropic magnetic susceptibility of rocks under mechanical stresses. Pure Appl. Geophys., 78, 110-122, doi: 10.1007/BF00874779. [Link]

Ogawa, Y., T. Yukutake, and H. Utada, 1986: Two-dimensional modelling of resistivity structure beneath the Tohoku district, northern Honshu of Japan, by a finite element method. J. Geomagn. Geoelectr., 38, 45-79, doi: 10.5636/jgg.38.45. [Link]

Parkinson, W. D., 1983: Introduction to Geomagnetism, Scottish Academic Press, Edinburgh, London, 433 pp.

Parkinson, W. D. and F. W. Jones, 1979: The geomagnetic coast effect. Rev. Geophys. Space Phys., 17, 19992015, doi: 10.1029/RG017i008p01999. [Link]

Stacey, F. D., 1962: Theory of the magnetic susceptibility of stressed rock. Philos. Mag., 7, 551-556, doi: 10.1080/14786436208212623. [Link]

Tsai, Y. B., T. L. Teng, J. M. Chiu, and H. L. Liu, 1977: Tectonic implications of the seismicity in the Taiwan region. Mem. Geol. Soc. China, 2, 13-41.

Wen, S., C. H. Chen, H. Y. Yen, T. K. Yeh, J. Y. Liu, K. Hattori, H. Peng, C. H. Wang, and T. C. Shin, 2012: Magnetic storm free ULF Analysis in relation with earthquakes in Taiwan. Nat. Hazards Earth Syst. Sci., 12, 1747-1754, doi: 10.5194/nhess-12-1747-2012. [Link]

Wu, F. T., 1978: Recent tectonics of Taiwan. J. Phys. Earth, 26, 265-299.

Yen, H. Y., C. H. Chen, Y. H. Yeh, J. Y. Liu, C. R. Lin, and Y. B. Tsai, 2004: Geomagnetic fluctuations during the 1999 Chi-Chi earthquake in Taiwan. Earth Planets Space, 56, 39-45, doi: 10.1186/BF03352489. [Link]

Yen, H. Y., C. H. Chen, H. H. Hsieh, C. R. Lin, Y. H. Yeh, Y. B. Tsai, J. Y. Liu, G. K. Yu, and Y. R. Chen, 2009: Magnetic survey of Taiwan and its preliminary interpretations. Terr. Atmo. Ocean. Sci., 20, 309-314, doi: 10.3319/TAO.2008.04.08.01(T). [Link]

Zeng, X. P., Y. F. Lin, Z. J. Zhu, C. R. Xu, M. Zhao, C. Y. Zhang, and Q. L. Liu, 1995: Study on electric variations of media in epicentral area by geomagnetic transfer functions. Acta Seismol. Sin., 8, 413-418, doi: 10.1007/BF02650569. [Link] 